\title{
Developing a 3D Decision Making Grid Based on Failure Modes and Effects Analysis With a Case Study in the Steel Industry
}

\author{
Arash Shahin* \\ Professor, Department of Management, University of Isfahan, Isfahan, Iran \\ Ashraf Labib \\ Professor, Department of Strategy and Business Systems, Portsmouth Business School, \\ Portsmouth, UK \\ Ali Haj Shirmohammadi \\ Visiting Professor at Simon Fraser University, Canada, and \\ Professor Emeritus at the Isfahan University of Technology, Iran \\ Hadi Balouei Jamkhaneh \\ Department of Management, University of Mazandaran, Babolsar, 4848154536, IR
}

\begin{abstract}
Purpose - The aim of this study is to develop a 3D model of decision making grid (DMG) considering failure detection rate.
\end{abstract}

Design/methodology/approach - In a comparison between DMG and Failure Modes and Effects analysis (FMEA), severity has been assumed as time to repair and occurrence as the frequency of failure. Detection rate has been added as the third dimension of DMG. Nine months data of 21 equipment of casting unit of Mobarakeh Steel Company (MSC) has been analyzed. Then, appropriate condition monitoring (CM) techniques and maintenance tactics have been suggested. While in 2D DMG, CM is used when downtime is high and frequency is low, its application has been developed for other maintenance tactics in a 3D DMG.

Findings - Findings indicate that the results obtained from the developed DMG are different from conventional grid results, and it is more capable in suggesting maintenance tactics according to the operating conditions of equipment.

Research limitations/implications - In failure detection, the influence of CM techniques is different. In this paper, CM techniques have been suggested based on their maximum influence on failure detection.

Originality/Value - In conventional decision making grid (DMG), failure detection rate is not included. The developed 3D-DMG provides this advantage by considering a new axis of detection rate in addition to MTTR and failure frequency and enhances maintenance decision making by simultaneous selection of suitable maintenance tactics and condition monitoring techniques.

Keywords: Decision Making Grid (DMG), Failure Modes and Effects Analysis (FMEA), Mean Time to Repair (MTTR), Frequency, Mobarakeh Steel Company (MSC) 


\section{Introduction}

With the progress of time, complexity in designing equipment and the ratio of automation, many skills are required, including the responsibility of bottom line employees towards equipment. Selecting and determining appropriate maintenance tactic based on failure ratio of equipment is one of the ways of decreasing unnecessary activities, and results in costs reduction (Shahin et al., 2018). Moreover, choosing appropriate maintenance tactic based on failure ratio increases the efficiency of equipment, which in turn leads to quality and quantity improvement of production systems. The term 'tactic' used in this paper is aligned with the study of Khazraei and Deuse (2011) who proposed a comprehensive model of maintenance strategies, policies and tactics.

Labib (1998), Fernandez et al. (2003), Labib (2004), Aslam-Zainudeen and Labib (2011), Stephen and Labib (2018) and Seecharan et al. (2018) considered Mean Time between Failures (MTBF) and Mean Time to Repair (MTTR) as the two time-based indicators of maintenance and classified his proposed tactics based on these two indicators. The tactics included Operate to Failure (OTF), Time Based Maintenance (TBM), Condition Based Maintenance (CBM), Design Out Maintenance (DOM) and Skill Level Upgrade (SLU). Labib named this matrix "Decision Making Grid (DMG)". MTBF indicates the mean time in which, the system operates without failure (Shahin and Attarpour, 2011; Karanikas, 2013); and MTTR indicates the mean time to the repair and when it is low, the equipment is repaired in shorter times (Shahin and Attarpour, 2011; Cheng and Kuan, 2012). It is important to note that compiling tactics based on these two indicators cannot be an appropriate solution in all conditions.

Some studies have been performed on developing DMG in recent years. Fernandez et al. (2003) prioritized each of the maintenance tactics of the grid cells by Analytic 
Hierarchy Process (AHP). Labib (2004) used a fuzzy DMG matrix for selecting optimum maintenance tactics. Tahir et al. (2009) applied tri-quadrant technique to cluster the DMG. They focused on the effect from the improvement of DMG model in categorizing low, medium and high criteria for the food processing companies of Malaysia. Shahin et al. (2011) investigated DMG considering the relationship between the two parameters of failure occurrence and severity using reliability functions. AslamZainudeen and Labib (2011) investigated the application of DMG in the domain of rotating parts maintenance in the railway industry. Shahin and Attarpour (2011) estimated Overall Equipment Effectiveness (OEE) indicator by regression and developed DMG based on MTBF and OEE. Burhanuddin et al. (2011) developed DMG further by considering repair cost as the third dimension of DMG in addition to MTTR and MTBF. Ghofrani Isfahani et al. (2013) integrated Six Sigma indicator and MTBF indicator. The major result of their study was more emphasizing on employees' skill level upgrade, and consequently employee training. Shahin et al. (2018) proposed a heuristic method and customized DMG for selecting proactive maintenance tactics. Shahin et al. (2019) studied the interdependence among failures and its impact on DMG.

While selecting maintenance tactics is a critical subject, the focus of the most of the available resources has been on the application of DMG or Multiple Attribute Decision Making (MADM) techniques. Some other studies attempted to resolve FMEA or CM weaknesses. For instance, Bogue (2013) investigated the application of technology and sensors in CM; vibration, voice, shock-pulse monitoring (SPM) and thermal monitoring. Cempel (2013) studied the application of Teoriya Resheniya Izobretatelskikh Zadatch (TRIZ), literally: 'theory of the resolution of invention-related tasks' in vibration CM. Bogue (2013) suggested the selection of CM strategies based on TRIZ contradiction 
matrix. Kumar and Chaturvedi (2011) prioritized maintenance strategies based on the risk of failure modes. They proposed a fuzzy approach for estimating Risk Priority Number (RPN).

While in risk management, one of the used techniques is Failure Modes and Effects Analysis (FMEA), it has been also applied for highly critical components, design modifications and maintenance actions in order to prevent failure causes or to mitigate their effects (Savino et al., 2011; Brun and Savino, 2018). Having compared the two approaches of DMG and FMEA, it seems that an indicator which has been remained unknown in DMG is the failure detection rate. The two approaches have been separately integrated with different methods; for instance, Savino et al. (2014) combined artificial intelligence with failure rates to choose maintenance policies. However, it seems no survey has been performed concerning the integration of these two approaches and particularly on developing DMG by FMEA. Therefore, the purpose of this study is to integrate the two indicators of DMG and failure detection rate of FMEA in order to select more effective tactics of maintenance. Thereby, a third dimension is added to the grid, so that this grid is developed, and failure detection rate can also be improved by Condition Monitoring (CM) techniques which has standard indicators. In fact, the new approach has this advantage that it can specify, as a key assumption, what kind of CM system should be used for equipment based on the condition of accessibility. Actually, the main aim is to find how 3D-DMG can be developed with regard to detection rate in RPN. Ultimately, the proposed model is analyzed in one of the processes of Mobarakeh Steel Company (MSC), and findings obtained from the analysis of 2D-DMG and 3DDMG are compared. Since by the use of the proposed approach, decision making on selecting CM approaches becomes more scientific based and related to time based indicators of MTTR and MTBF, the new approach is expected to reduce the risk of 
wrong maintenance decision making, which in turn results in cost effective maintenance.

\section{Decision Making Grid (DMG)}

DMG is a tracing technique for supporting decision making in a maintenance system. In this matrix, performance of equipment is analyzed based on two indicators of downtime and failure frequency (Figure 1).

\section{"Take in Figure 1"}

Depending on the location of performance of desired equipment in the grid, the favorable maintenance tactic is proposed as the best possible solution (Labib, 1998; Fernandez et al., 2003).

\section{Failure Modes and Effects Analysis (FMEA)}

FMEA is an analytical technique based on "prevention before occurrence" rule, applied for identifying potential failures (Filho et al., 2017). Using this technique increases safety rate, and ultimately customer satisfaction by preventing failure occurrence. FMEA is a technique that is applied at the stages of design and development of processes and services in the organization (Dorri et al., 2010).

Risk Priority Number (RPN) is the result of multiplying severity, occurrence and failure detection rate (Lorenzi and Ferreira, 2018). Severity is the critical rate of failure 
effect which is usually observed in three categories of user safety, equipment failure, and failure of a part of the equipment. It should be noted that for issues related to safety, severity is always high, and comparison system is used for the failure of a component of equipment. Occurrence is the possibility of a failure mode happening while equipment is working due to a defined reason. Detection rate is the ability of design controls or equipment in discovering and identifying failure cause or failure mode. An RPN value does not mean anything by itself; it is meaningful when it is compared with other RPNs (Lee and Chen, 2007).

It is important to note that FMEA needs a strong multidisciplinary team, including a leader and members from different professional backgrounds with wide collective experience (Alamry et al., 2017; Simsekler et al., 2019).

\section{Condition Monitoring (CM)}

By using sensors and performance monitoring systems, the testability level of equipment is increased (Hernandez and Labib, 2017). Having obtained such knowledge related to condition of equipment, the primary failures can be predicted and removed.

The objective of condition monitoring is to determine the correctness of the operating states of physical assets and manufacturing processes (Cao et al., 2019). In fact, the main aim of CM strategies is to ensure that the equipment are working under effective and defect free condition. One of the strategies is measurement and analysis of vibrations (Yunusa-kaltungo and Sinha, 2017). Vibrations are appeared as rotational movements of a machine or a set of machines regarding their reliance point (Mobley, 2002). In most of the mechanical and hydraulic systems, there is a flow of oil lubricant during the operations that reduces friction between the two surfaces that slide against 
each other. This will considerably reduce the wasted energy and equipment disconnections (Variani Farahani, 2007). However, the lubrication flow, lubrication pressure and lubrication temperature require a proper monitoring scheme (Almasi, 2015).

$\mathrm{CM}$ includes a wide range of techniques from utilizing five human senses to using advanced computerized tools in order to prevent potential failures and to implement a maintenance system in confrontation with potential failures (William et al., 1994). Regarding the above explanation, in this study the most comprehensive set of CM techniques stated by Kelly (2006) is used (Table 1).

"Take in Table 1"

\section{New methodology}

The new methodology is based on failure frequency of equipment; MTTR (in hour), failure detection rate; and CM indicators. The data related to frequency, MTTR of each equipment is collected according to the documents of MSC, and the data related to failure detection rate, and CM techniques is collected using questionnaire. In this investigation. It is essential to mention that frequency is used instead of MTBF since frequency of failures seems more comprehensive than MTBF (Hansen, 2005).

In this study, the conventional DMG proposed by Labib (1998) is used in which, the frequency of failures and MTTR are the two main indicators. In DMG, failure frequency and MTTR are divided into three categories of low, medium, and high levels, and the cross of these three levels forms nine cells. In each cell, a type of maintenance tactic is suggested. In this study, for the purpose of integrating FMEA and DMG, it is 
assumed that severity is the same as repair time, i.e. MTTR, and failure occurrence is the same as frequency or the reverse of MTBF. It is important to note that there might be also other bases for determining severity, such as cost of lost production and cost to repair, but the reason for such assumption was due to the fact that authors tried to propose their approach based on DMG, which is a time based framework. In addition, in order to develop DMG, failure detection rate of FMEA as the third dimension is added to the two dimensions of conventional DMG.

Failure detection is the ability of equipment or design controls to explore the causes of failures or the modes of failures (Lee and Chen, 2007). Failure detection rate dimension is also improvable by $\mathrm{CM}$ techniques that have standard indicators, and regarding the relationship that exists between these indicators, a new model is introduced for choosing appropriate maintenance tactic. The proposed model of this study is illustrated in Figure 2. While apparently in Figure 2, the tactics to be employed are the same at each level of detection, depending on the determined levels for failure detection rate, the range of $\mathrm{CM}$ techniques would be different. This is explained in the next section in Tables 2 and 3. Since it was difficult to address all techniques in the figure, authors merely represented the three determined levels of detection rate on the left side of the figure.

\section{"Take in Figure 2"}

In general, in DMG, for the OTF cell the proposed strategies are prioritized according to low cost objective. On this basis, in the designed model for equipment placed in this cell, first each of the proposed CM techniques are investigated in respect of appropriateness with the nature of failures of each equipment, and after primary screening, by comparing the suggested techniques and existing techniques of the 
company, a suitable technique for the equipment is proposed. For FTM cell, the techniques are prioritized based on time. In fact experts by balancing time-cost, choose favorable technique(s) for equipment. In CBM cell in which, the major objective is increasing reliability, the role and place of CM is more important than in the other cells. In this cell, the basis of prioritizing techniques is $\mathrm{CM}$ effectiveness which is much more important than time and cost. For SLU cell the techniques are prioritized with regard to skill level defined for operators. In DOM cell the basis of prioritizing techniques is also the balance between CM cost and replacement cost of the components of equipment. The research steps are illustrated in Figure 3.

"Take in Figure 3"

As illustrated in Figure 3, first the literature on techniques for CM, DMG, and FMEA are reviewed. Then, RPN is matched with the dimensions of 2D-DMG and then, considering the criteria of detecting failures in RPN, the 3D-DMG is developed. Then, according to the failure detection rate, appropriate techniques of $\mathrm{CM}$ are determined for each level. In addition, the technique formulation is performed simultaneously with the investigation of the application of the proposed approach in the casting unit of MSC. Finally, the results of the investigation of conventional and developed DMGs are compared.

\section{Case study and findings}

The statistical population of this study included all equipment maintenance indicators in all units and workshops of MSC, and the population of experts included five managers 
and 10 employees of the maintenance section of MSC related to the casting unit and also seven professors of the University of Isfahan who had conducted research projects at the casting unit under the university-industry contracts.

The method of sampling maintenance indicators was purposeful and non random sampling. Totally, 21 equipment of the casting unit of MSC were introduced by the company for examining the proposed approach. The introduced equipment had the highest rates of major stoppage. For developing DMG, the viewpoints of the experts were utilized.

In order to collect data on the importance of $\mathrm{CM}$ techniques, the whole population, i.e. 22 experts were asked to fill the CM questionnaire. The CM questionnaire was arranged according to nine point spectrum and the data related to this questionnaire was used for developing the conceptual model. Since the CM questionnaire was developed based on Kelly (2006), merely formal validity was checked and confirmed by the experts. In addition, since the whole population of experts was asked to fill questionnaires, there was no need to examine data reliability. In order to determine failure detection rate of equipment, a questionnaire was used and after collecting viewpoints, the decuple spectrum was transformed into a nine point spectrum. In this study, in order to analyze the data of MTTR and failure frequency, descriptive statistics were used. In the section of analyzing DMG data and RPN, SPSS18 and Matlab software were used.

The data was collected from the casting unit of MSC in a nine months; so that for each equipment, the description of failure type, description of failure reason, failure number, and mean time of each failure were collected separately, and in line with the study, such data was summarized. The data was recorded in and collected from the Computerized Maintenance Management System (CMMS) of the company. For MTTR indicator, the highest and lowest values were 5.35 and 0.65 , respectively. For frequency indicator, the 
highest and lowest values were 33 and 1, respectively. Considering the formula suggested by Fernandez et al. (2003), the values were divided into three levels of low, medium, and high. The summarized data was then used in the developed DMG.

As it is illustrated in Figure 4, most of the equipment had low MTTR and failure frequency, and based on the conventional DMG, emergency maintenance was suggested for most of the equipment, so that out of the 21 equipment under investigation, nine equipments were placed in the OTF cell, and afterwards, FTM, CBM, SLU tactics were suggested for other equipment. As it is addressed, DOM was not suggested for any equipment.

"Take in Figure 4"

6.1 Analyzing developed 3D-DMG considering failure detection rate

As it is shown in Table 2, based on determined boundaries, failure detection rate axis was divided into three levels, and ultimately it was added to the developed model. According to the FMEA approach, a standard spectrum of 1 to 10 should be used for determining the detection rate. For this purpose, a questionnaire was developed and experts were asked to rate the failure detection by related CM technique. Since authors used Fernandez et al. (2003) approach to determine the range of detection rate related axis in the developed DMG, they preferred to set absolute values for the cutting points. Therefore, a nine point spectrum was better than a 10 point spectrum. Ultimately, authors used a fit ratio to convert collected data based on 10 point spectrum to data based on a nine point spectrum. 


\section{"Take in Table 2"}

Suitable CM techniques were suggested with regard to the determined levels of failure detection rate, the detection rate of determined failure for each equipment, and the impact ratio of each $\mathrm{CM}$ technique on failure detection rate, appropriate with the level of failure detection rate. Another words, considering Table 3, the higher the failure detection rate for each equipment, the simpler $\mathrm{CM}$ technique is required for failure detection; and vice versa, the lower the detection rate for each equipment, the more complex CM technique is required to reach the suitable condition. It should be noted that while CM techniques are mostly applied in CBM, if maintenance decision makers decide to apply them together with other tactics, the proposed approach provides such opportunity. However, prior to the proposed approach, the main question was 'based on what range of detection rate related to MTBF and MTTR, what type of CM tools and techniques should be applied?' This important question seems answered in this study.

"Take in Table 3"

6.2 Developed 3D-DMG considering level one of failure detection rate

As it was emphasized earlier, each level was investigated separately. To determine the place of each tactic in the developed model, for each tactic, three indexes were defined. The first index indicated the level related to MTTR; second index was related to frequency; and third index was related to detection rate.

Based on the results and according to Figure 2, since levels 1 to 3 have highest detection rate, the first level of the 3D-DMG is suggested and consequently, polarization 
resistance, spectroscopy, weight loss coupons and incremental bore holes techniques of $\mathrm{CM}$ were suggested for this level, and by more accurate investigation in each of the cells, suitable technique was determined for each equipment by comparing the proposed $\mathrm{CM}$ techniques with the existing techniques used by the company. For the cell $\mathrm{OTF}_{1,1,1}$, after investigating the appropriateness of suggested CM techniques, with the nature of equipment failures, and comparing them with the existing techniques used by the company, the results for the equipment of cell $\mathrm{OTF}_{1,1,1}$ were obtained as addressed in Table 4. Thus, this action was also performed for other cells of level one of the developed model, with this difference that for each of the cells, the basis of prioritizing techniques is different. It is essential to mention that since no equipment was located in cell $\mathrm{DOM}_{3,3,1}$, no associated analysis was performed. The results of investigating equipment and suggested techniques related to the cells of level one of failure detection rate are presented in Table 4.

"Take in Table 4"

Considering the suggested techniques, it was found that polarization resistance method and spectroscopy of CM techniques had relatively higher frequency. This means that most of the equipment required care in corrosion detection domain and in determining level of chemical lubricant. In addition, it was possible that such equipment could be damaged in the two domains.

6.3 Developed 3D-DMG considering level two of failure detection rate 
Since the second level of failure detection rate is between 3 and 6, regarding Table 4, suitable CM techniques were suggested for this level. At this level, like level one, the basis of prioritizing techniques was also different. With regard to the performed investigations, it became obvious that the equipment with code 14 was located in cell $\mathrm{OTF}_{1,1,2}$. At this level, $\mathrm{CM}$ techniques were prioritized according to cost, and then in order to suggest suitable technique for equipment with code 14, they were compared with the existing techniques used by the company. The results of this survey indicated that optical probes and closed circuit were suitable for the equipment with code 14 .

\subsection{Developed 3D-DMG considering level three of failure detection rate}

Considering the point that level three of failure detection rate is between 6 and 9; i.e., failure detection is at lower level, therefore it requires a complex $\mathrm{CM}$ technique. Thus, human eye, dye penetrant (penetrate dye), thermometers, and thermocouples, overall vibration level, and radiography of CM techniques were suggested for this level. At this level similar to level one, the basis of prioritizing techniques was also different. It is important to mention that since no equipment was located in the cells, no associated analysis was performed.

As mentioned earlier, the higher the failure detection rate for equipment, simpler $\mathrm{CM}$ techniques are required for failure detection, and conversely, the lower the failure detection rate for equipment, the more complicated $\mathrm{CM}$ techniques are required to achieve desired conditions. The lowest level of failure detection was at level 3. So it was necessary to chose more complicated $\mathrm{CM}$ techniques. In the following, the suggested CM techniques for level 3 are described.

Human Eye covers a wide variety of methods for surface inspection and CM with high effectiveness. The Thermometers-Thermocouples method encompasses a wide range of 
instruments, from thermometers installable on the equipment to the thermocouples sensors. This method is used for reading the temperature of the equipment. It also provides the electrical input required for a hardware system of equipment monitoring. Dye Penetrant is used to the detection of cracks that could lead to the fracture of items. The Radiography method is used for the detection of cracks anywhere in the parts, although access to both sides of the part is necessary in this method. In this approach there is a danger of radioactivity. The Overall Vibration Level method determines the vibration of rotating or moving equipment. By estimating the pattern and procedure of these vibrations, the common failures of equipment are identified, but determining the causes of failures is impossible by this method, so the ability of this method in detecting failure is not high.

In the developed 3D-DMG, RPN was obtained by multiplying MTTR by frequency by failure detection rate, and the results are addressed in Table 5. For example, for Primary Cooling, the multiplication of the values of $1.47,16$ and 2.7 would be 63.50 . In this table, a value was also calculated for the conventional 2D-DMG by multiplying MTTR by frequency. For example, for Primary Cooling, the multiplication of the values of the

\subsection{7 and 16 would be 23.52 .}

According to Table 5, about $80 \%$ of frequencies was related to the equipment with codes $01,08,23,04,02,09,18,21$, and 25 . In addition, most of the equipment was located in areas related to low MTTR, low failure detection rate, and varied frequency.

\footnotetext{
"Take in Table 5"
} 
As it is observed in Table 6, the rankings of equipment are compared regarding 2DDMG and 3D-DMG. The rankings are based on the sorted DMG and RPN values in the two last columns of Table 5. As it is clear for 12 equipment, rankings are different.

\section{"Take in Table 6"}

As it is observed in Figure 5, based on the Pareto principle, the equipment were divided into two groups. The first group, i.e. the equipment outlined by triangles indicated that $20 \%$ of equipment had the majority of frequency $(80 \%)$; and the equipment outlined by circles indicated that they were less important compared to the equipment of the first group. In this section, most of the equipment were also located in low frequency cell, and low MTTR cell.

As it is illustrated in Figure 6, the distribution mode of equipment under investigation based on frequency, MTTR, and failure detection rate indicators were represented in a three dimensional area. Similarly, most of the equipment were located in the area related to low MTTR, low failure detection rate, and varied frequency. This means that equipment downtime did not follow any special distribution, and it is accidental; thus, for such cases, selecting a maintenance tactic with constant time intervals seems reasonable. Based on the Pareto principle, $20 \%$ of equipment which allocated $80 \%$ of RPN were underlined in a three dimensional area with codes $01,08,23,18,04,09,21$ and 25 .

"Take in Figure 5" 


\section{"Take in Figure 6"}

\section{Discussion}

Findings indicated that equipment with codes $13,19,05,10,16,12,07$, and 11 were located in $\mathrm{OTF}_{1,1,1}$ cell; equipment with codes 25,29 , and 09 were located in $\mathrm{FTM}_{2,1,1}$ cell; equipment with codes 20 and 23 were located in $\mathrm{CBM}_{3,1,1}$ cell; equipment with codes 24, 02, 21, and 18 were located in $\mathrm{FTM}_{1,2,1}$ cell; equipment with code 08 was located in FTM2,2,1 cell; equipment with code 04 was located in SLU1,3,1 cell; and ultimately equipment with code 01 was located in $\mathrm{FTM}_{3,2,1}$ cell.

Since levels 1 to 3 had the highest detection rate, polarization resistance, spectroscopy, weight loss coupons, and incremental bore holes were suggested for this level, and by more accurate investigation in these cells, suitable technique for equipment was determined by comparing the suggested and existing CM techniques. Since the failure detection rate was between 3 and 6, the optical probes, SPM, spike energy and kurtosis, infrared camera, magnetic flux, infrared meter, ultrasonic, structural monitoring, temperature crayons, paints and tapes, eddy currents, magnetic plugs and filters, closed circuit television (CCTV), frequency (spectrum) analysis, electrical resistance (corrosion), ferrography (iron survey) and electrical resistance (gap survey) were suggested for this level. At this level, similar to the first level, considering defined cells, the basis of prioritizing techniques was different. With regard to performed investigations, it became clear that the equipment with code 14 was located in $\mathrm{OTF}_{1,1,2}$ cell. At this level, based on cost, the CM techniques were prioritized, and then they were compared with existing techniques of the company, so that the suitable technique was proposed for equipment with code 14 . Considering the point that at the third level, failure detection rate was between 6 to 9 ; in other words failure detection was at lowest 
limit, a strong CM technique was required. Thus, human eye, dye penetrant (penetrate dye), thermometers and thermocouples, overall vibration level and radiography of $\mathrm{CM}$ techniques were proposed for this level. At this level, similar to the first level, considering defined cells, the basis of prioritizing techniques was different.

According to the findings, most of the equipment required OTF and then FTM. At the first level of failure detection rate (1-3 level), the highest frequency was associated with Polarization Resistance and Spectroscopy. Polarization Resistance is one of the techniques for measuring corrosion. This method has a good application in corrosion detection, but it is not much reliable, because it is a means to estimate the rate of material loss. Spectroscopy is a technique for lubricant control, and is an analytical method used in the determination of the chemical compositions of lubricant and metal particles. Generally this method is used for small metal particles with sizes of 0 to 10 micrometers, and often, these services are assigned to contractors. At the second level of failure detection rate (3-6 level), the highest frequency was associated with Optical Probes and Closed Circuit Television (CCTV) techniques, among visual techniques. Optical Probe is used for internal inspection of machines and is appropriate for detection of surface corrosion, erosion, and high-intensity defects such as cracks. Closed Circuit Television is used in the inspection of the details of parts that are not available and are dangerous. It also has the ability to capture and analyze the high resolution and yet is a post-process method (i.e. in order to use this method, the process should have been accomplished).

The CM techniques that are currently used in MSC for the studied equipment include: Vibration Analysis, Thermography, Inspection Standard, and Service Standard. The associated tools are addressed in Table 7. 


\section{"Take in Table 7"}

As it was observed in Figure 4, most of the equipment required OTF and the next most frequent tactic was FTM. As Table 6 indicated, the rankings of equipment were different for 12 equipment in 2D-DMG and 3D-DMG. This underlines the fact that the findings of the developed DMG might lead to a more effective decision on the selection of maintenance tactics compared to the conventional DMG, particularly due to the fact that the decision will be made based on more information, i.e. the third dimension of detection rate. In addition, the developed DMG includes CM techniques which is an important advantage over the conventional DMG. Having compared the conventional and new DMGs with RPN, it should be stated that since the range is linear, the basic limitation of RPN might occur; i.e. two equipment with equal RPN might exist.

Ghofrani Isfahani et al., (2013) performed determination of suitable maintenance tactics with regard to MTTR, Six Sigma indicators and process capability indicator; while in this study by using a comparative analysis between DMG indicators and RPN, the indicator of FMEA was used and the new DMG was developed. Another difference of these two studies is that in this paper by using suitable CM techniques, due to the cause and type of failure in each equipment and also the determined levels based on failure detection rate, suitable techniques were addressed. Another similar study is Shahin et al. (2011), in which maintenance tactics were prioritized, while the differences between equipments in respect of dependency and mutual impact were not recognized and the concentration was more on the relationships among tactics. Literature review indicates that in studies on DMG, investigations of Labib (1998), Labib (2004) and Labib (2011) were widely used, which represent the basics of DMG, while because of using failure detection rate and $\mathrm{CM}$ techniques, the proposed $\mathrm{DMG}$ is a developed version, and 
provides more effective techniques/tactics based on the conditions of equipment. Shahin and Attarpour (2011) in a survey re-planned DMG based on Overall Equipments Effectiveness (OEE), and considering OEE, they used quality rate, speed and availability; however, they did not consider failure detection rate and did not suggest any $\mathrm{CM}$ technique for equipment compatible with the cause and type of failure.

With regard to the findings, based on developed 3D-DMG, most of the equipment required OTF tactic. Therefore, discovering the place of failure and separating it from other sections is more important, so that immediately after recognizing the reason and place of failure, attempt should be made to repair and reconstruct the failure part. In order to upgrade employees' skill level, the production operators should be trained for primary maintenance of equipment. Holding training courses and participating in seminars in order to become acquaintance with $\mathrm{CM}$ techniques are recommended for upgrading employees' skill level and awareness. For the equipment requiring maintenance tactic of CBM, not only the cost of modifying methods of repair, but also the cost of missed opportunity should be considered for decision making. Motivating and increasing responsibility sense in production operators towards equipment for primary maintenance actions and making them sensitive in order to minimize the cost of OTF are also important.

\section{Conclusions}

Major finding of this study indicates the difference between two and three dimensional DMGs. It seems disregarding failure detection rate in conventional DMG can reduce the degree of freedom in decision making in estimation and determination of maintenance tactics and CM techniques. Therefore it seems that the proposed approach is a more complete version of DMG. 
Major similarities of the conventional and developed DMG are as follows:

- the two grids were similar in terms of the indicators of failure frequency and MTTR;

- based on the research findings, in both DMGs, DOM was not proposed for any equipment; and

- the axes of the two grids were calculated similarly.

In addition, major differences between the conventional and proposed DMGs include:

- the new DMG is based on three indicators of failure frequency, MTTR, and failure detection rate, while the conventional DMG was based on two indicators of failure frequency and MTTR;

- in the developed DMG, the tactics are divided into three categories based on the level of failure detection rate, and the suitable CM techniques are proposed according to each level; and

- since the visualization of spatial analysis of RPN is impossible in two-dimensional form, the application of three-dimensional DMG has more advantage over the conventional DMG.

Among the limitations of this study is that prioritizing CM techniques was independent from the under study equipment. Another limitation of this study is that nothing was stated concerning the effectiveness of $\mathrm{CM}$ and a concentration was made merely on suggesting CM techniques. This study was limited to the analysis of RPN indicator. Of the 21 equipment that were to be maintained, 20 were in one layer and therefore the applicability of the 3D grid was effectively limited to one layer. The problem that the authors were dealing with initially before selecting the case study was the availability of field data on the two indicators of MTBF and MTTR. The company wherein the case 
study was performed was the best choice regarding this important issue, while even within the company not all sections/sites had enough data for the purpose of 3D-DMG.

Given the high similarity that exists between PokaYoke and CM techniques, it is recommended as a suggested subject for future studies to consider PokaYoke as a method of CM, such a way that to increase the level of failure detection, the PokaYoke methods can be used proportional to the cause of the failure of each equipment in addition to CM techniques. Also, it is suggested that in future studies, the cost of all tactics addressed in the DMG be estimated. This is particularly important for costbenefit analysis of the tactics, since due to the use of CM techniques, the shift from one tactic to another one could be postponed and the trend and speed of movement in the cells of DMG could be changed by this policy.

It seems that in future studies, a weight can be estimated/assumed for the ratio of $\mathrm{CM}$ techniques depending on equipment. In RPN, the range of each of the indicators of severity, occurrence, and failure detection rate was assumed from 1 to 10 , while in DMG, no high limit is defined for failure occurrence or failure frequency indicators. For instance the failure frequency of an equipment might be 30 , hence in the new approach, the RPN score might be beyond 1000. It is suggested that in future studies, the occurrence indicator be equalized with the same frequency like what was performed in this study for failure detection rate based on the nine point spectrum. In this case, considering the point that two indicators of severity and detection rate were arranged according to nine point spectrum, the high limit of RPN can be 729 (i.e. $9 \times 9 \times 9$ ) not 1000. In this paper, severity was assumed as MTTR, and with regard to this fact that MTTR is measurable; the application of reverse dual questionnaire of Kano model (Shahin, 2004) seems useless. Regarding the Kano model, it is suggested to compare MTTR's nine point options spectrum with various dimensions of the Kano model in 
future studies, and resolve the problem of constant and equal axis intervals by allocating nonlinear weights to each of the dimensions of DMG. Since the results were mostly limited to a single level of the 3D-DMG, and this was due to the typical case study, performing this study in other companies with various conditions of equipment regarding MTBF and MTTR values, can be helpful in adopting the new approach with more validity.

\section{Acknowledgements}

The authors appreciate the support of MSC in its careful and valuable contribution to the evaluation of the proposed framework. Special acknowledgements to Mr. Farhad Anvari, director of Research and Development Center; Mr. Rasoul Shafeizadeh, director of Maintenance Department and Mr. Rezaei, expert of the Casting Department.

\section{References}

Alamry, A., Al Owais, S.M., Marini, A.M., Al-Dorzi, H., Alsolamy, S. and Arabi, Y. (2017), "Application of Failure Mode Effect Analysis to improve the care of septic patients admitted through the emergency department", Journal of Patient Safety, Vol. 3 No. 2, p. 76.

Almasi, A. (2015), Latest lessons learned, modern condition monitoring and advanced predictive maintenance for gas turbines, Australian Journal of Mechanical Engineering, Vol.14 No.3, pp. 199-211.

Aslam-Zainudeen, N. and Labib, A. (2011), "Practical application of the decision making grid", Journal of Quality in Maintenance Engineering, Vol.17 No.2, pp. 138149. 
Bogue, R. (2013), "Sensors for condition monitoring: a review of technologies and applications", Sensor Review, Vol. 33 No. 4, pp. 295-299.

Burhanuddin M.A. Halawani, S.M. and Ahmad, A.R. (2011), "A costing analysis for decision making grid model in failure-based maintenance", Advances in Decision Sciences, doi:10.1155/2011/205039.

Brun, A. and Savino, M. (2018), "Assessing risk through composite FMEA with pairwise matrix and Markov chains", International Journal of Quality and Reliability Management, Vol. 35 No. 9, pp. 1709-1733.

Cao, Q., Giustozzi, F., Zanni-Merk, C., Beuvron, F.D.B.D. and Reich, C. (2019), Smart condition monitoring for industry 4.0 manufacturing processes: an ontology-based approach, Cybernetics and Systems, DOI: 10.1080/01969722.2019.1565118.

Cempel, C. (2013), "Application of TRIZ approach to machine vibration condition monitoring problems", Mechanical Systems and Signal Processing, Vol. 41 No. 1/2, pp. 328-334.

Cheng, C.S. and Kuan, C.M. (2012), "Research on product reliability improvement by using DMAIC process: A case study of cold cathode fluorescent lamp", Asian Journal on Quality, Vol. 13 No. 1, pp. 67-76.

Dorri, B., Moazzaz, H. and Salaami, H. (2010), “An integrated approach of risk analysis using Failure Modes and Effects Analysis and Analytic Network Process", Journal of Management Research in Iran, Vol.14 No.4, pp. 107-136.

Fernandz, O., Labib, W., Walmsley, R. and Petty, D. (2003), "A decision support maintenance management system developing and implementation", International Journal of Quality and Reliability Management, Vol. 20 No. 8, pp. 965-979. 
Filho, B.J.C., Piechnicki, F., Loures, E.deF.R. and Santos, E.A.P. (2017), "Processaware FMEA framework for failure analysis in maintenance", Journal of Manufacturing Technology Management, Vol. 28 No.6, pp. 822-848.

Hansen, R.C. (2005), Overall Equipment Effectiveness (OEE), Industrial Press.

Hernandez, M.D.P.C. and Labib, A. (2017), "Selecting a condition monitoring system for enhancing effectiveness of power transformer maintenance", Journal of Quality in Maintenance Engineering, Vol. 23 No. 4, pp. 400-414.

Karanikas, N. (2013), "Using reliability indicators to explore human factors issues in maintenance databases", International Journal of Quality and Reliability Management, Vol. 30 No. 2, pp. 116-128.

Kelly, A. (2006), Strategic Maintenance Planning, Butterworth-Heinemann, London.

Kumar, E.V. and Chaturvedi, S.K. (2011), "Prioritization of maintenance tasks on industrial quipment for reliability: A fuzzy approach", International Journal of Quality and Reliability Management, Vol. 28 No. 1, pp. 109-126.

Khazraei, K. and Deuse, J. (2011), “A strategic standpoint on maintenance taxonomy”, Journal of Facilities Management, Vol. 9 No. 2, pp. 96-113.

Labib A.W. (1998), "World-class maintenance using a computerized maintenance management system", Journal of Quality in Maintenance Engineering, Vol.4 No.1, pp. 66-75.

Labib, A.W. (2004), "A decision analysis model for maintenance policy selection using a CMMS", Journal of Quality in Maintenance Engineering, Vol.10 No.3, pp. 191-202.

Labib, A.W. (2008), “Computerized Maintenance Management Systems”, in K.A.H. Kobbacy and D.N.P. Murthy (eds), Complex Systems Maintenance Handbook, Springer. 
Lee, C.Y. and Chen, K.J. (2007), "Utility priority number evaluation for FMEA", Journal of Failure Analysis and Prevention, Vol.7 No.5, p. 321-328.

Lorenzi, C.I. and Ferreira, J.C.E. (2018), "Failure mapping using FMEA and A3 in engineering to order product development", International Journal of Quality and Reliability Management, Vol.35 No.7, pp. 1399-1422.

Mobley, K.R. (2002), An Introduction to Predictive Maintenance, Second Edition, Plant Engineering, Hardcover.

Savino, M.M., Brun, A. and Riccio, C. (2011), "Integrated system for maintenance and safety management through FMECA principles and fuzzy inference engine", European Journal of Industrial Engineering, Vol. 5 No. 2, pp.132-169.

Savino M.M., Mazza, A. and Neubert, G. (2014), “Agent-based flow-shop modelling in dynamic environment”, Production Planning and Control, Vol. 25 No. 2, pp. 110-122.

Seecharan, T., Labib, A. and Jardine, A. (2018), "Maintenance strategies: Decision Making Grid vs. Jack-Knife Diagram", Journal of Quality in Maintenance Engineering, In press, https://doi.org/10.1108/JQME-06-2016-0023.

Shahin, A. (2004), "Integration of FMEA and the Kano model: An exploratory examination", International Journal of Quality and Reliability Management, Vol.21 No.7, pp. 731-746.

Shahin, A., Aminsabouri, N. and Kianfar, K. (2018), "Developing a Decision Making Grid for determining proactive maintenance tactics: A case study in the steel industry", Journal of Manufacturing Technology Management, Vol. 29 No. 8, pp.1296-1315.

Shahin, A. and Attarpour, M.R. (2011), "Developing decision making grid for maintenance policy making based on estimated range of overall equipment effectiveness”, Modern Applied Science, Vol.5 No.6, pp. 86-97. 
Shahin, A., Ghofrani Isfahani, N. and Nilipour Tabatabaei, S.A. (2013), "Determining appropriate maintenance strategy based on decision making grid, Sigma level, and process capability index - with a case study in a steel company", International Journal of Applied Management Science, In Press.

Shahin, A., Labib, A., Emami, S., Karbasian, M. (2019), "Improving Decision-Making Grid based on interdependence among failures with a case study in the steel industry", The TQM Journal, Vol. 31 No. 2, pp.167-182,

Shahin, A. Pourjavad, E. and Shirouyehzad, H. (2012), "Selecting optimum maintenance strategy by analytic network process with a case study in the mining industry”, International Journal of Productivity and Quality Management, Vol.10 No.4, pp. 464-483.

Shahin, A., Ranjbar, M.J. and Abedi, S. (2011), "Critical discussion on the relationship between failure occurrence and severity using reliability functions, Management Science and Engineering, Vol.5 No.1, pp. 26-36.

Simsekler, M.C.E., Kaya, G.K., Ward, J.R. and Clarkson, P.J. (2019), "Evaluating inputs of failure modes and effects analysis in identifying patient safety risks", International Journal of Health Care Quality Assurance, doi:10.1108/ijhcqa-12-20170233.

Stephen, C. and Labib, A. (2018), "A hybrid model for learning from failures", Expert Systems with Applications, Vol. 93 March, pp. 212-222.

Tahir, Z., Burhanuddin, M.A., Ahmad, A.R., Halawani, S.M. and Arif, F. (2009), "Improvement of Decision Making Grid model for maintenance management in small and medium industries", Proceedings of the International Conference on Industrial and Information Systems (ICIIS), IEEE, pp. 598-603. 
Varani Farahani, H. (2007), "Fundamentals of designing and implementing conditionbased maintenance in industrial units - Case Study: Shazand thermal power plant", Proceedings of the $2^{\text {nd }}$ Technical Conference and Troubleshooting Machinery Condition Monitoring, Sharif University of Technology, Tehran.

Williams, J.H., Davies, A. and Drake, P.R. (1994), Condition Based Maintenance and Machine Diagnostic, Chapman \& Hall, London.

Yunusa-kaltungo, A. and Sinha, J.K. (2017), "Effective vibration-based condition monitoring (eVCM) of rotating machines", Journal of Quality in Maintenance Engineering, Vol.23 No.3, pp. 279-296. 


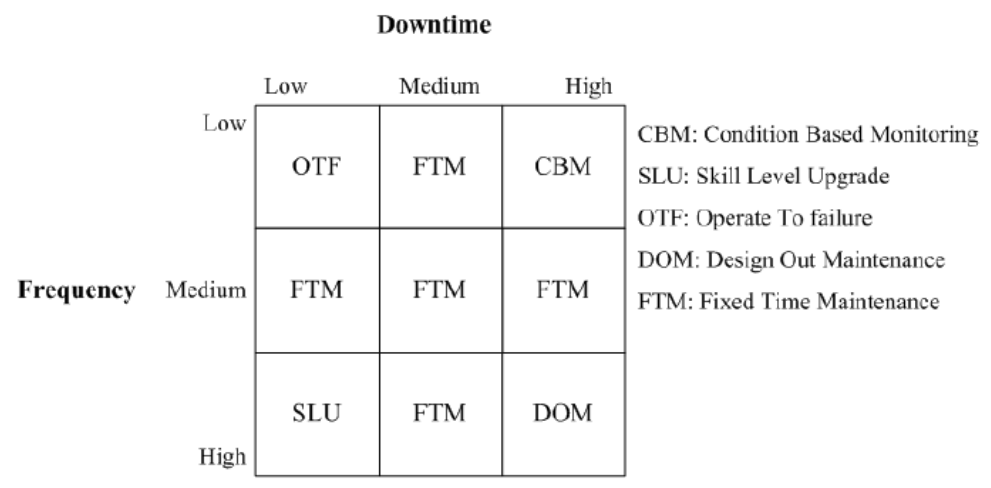

Figure 1. DMG (Aslam-Zainudeen and Labib, 2011)
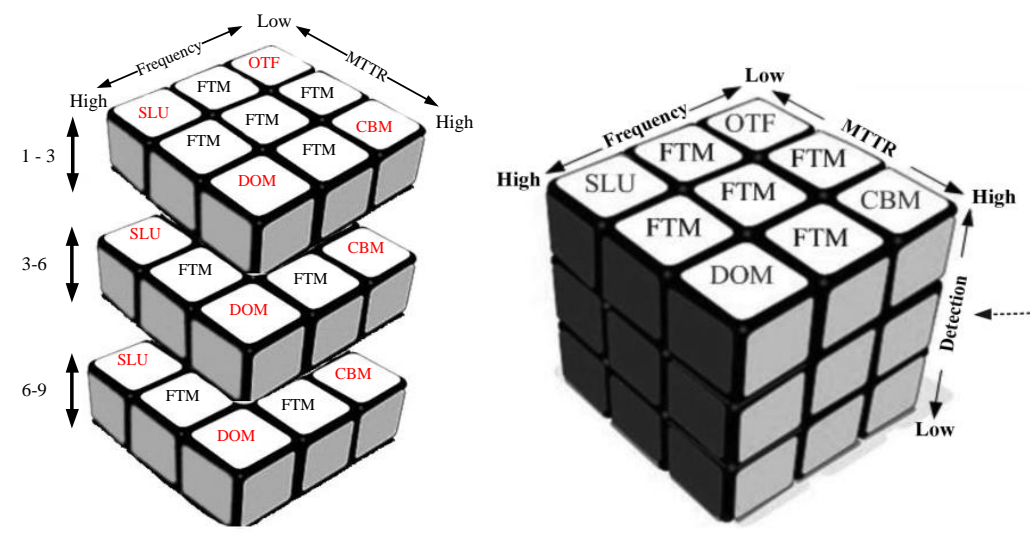

FMEA

Figure 2. Proposed 3D form of DMG 


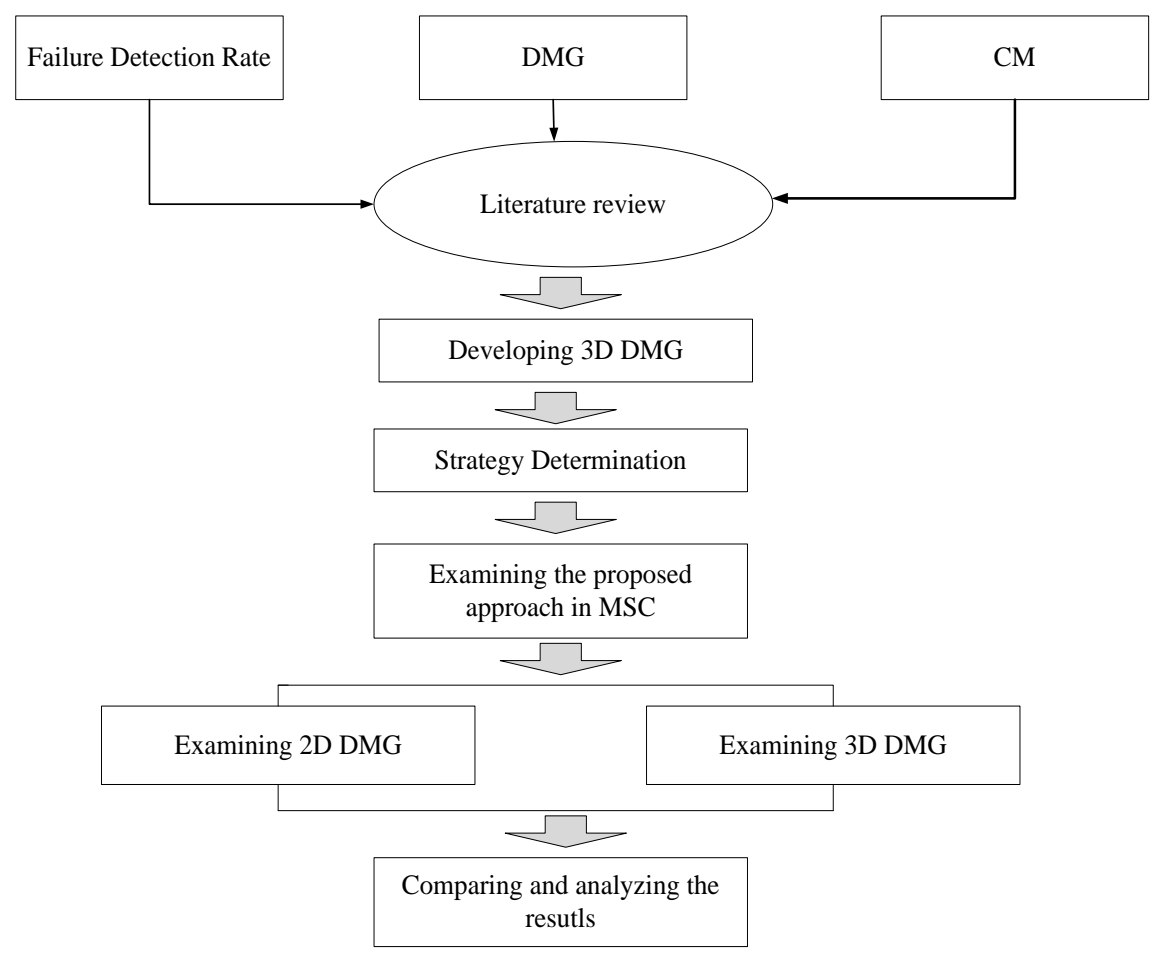

Figure 3. Executive framework of research

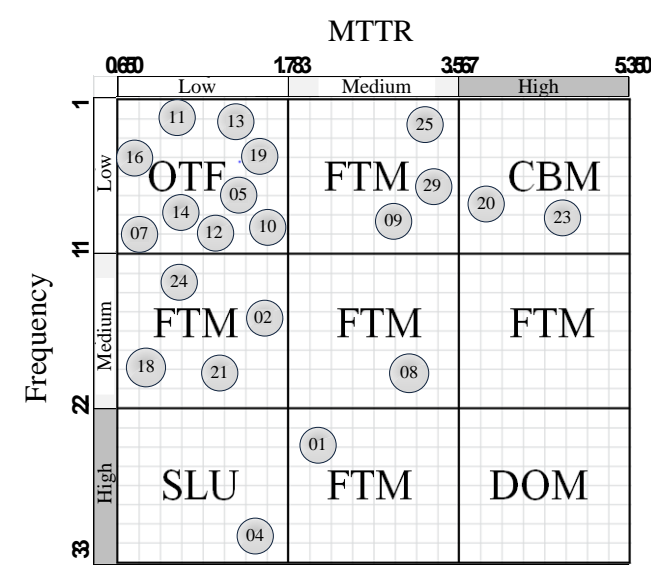

Figure 4. Placement of equipments based on the traditional DMG

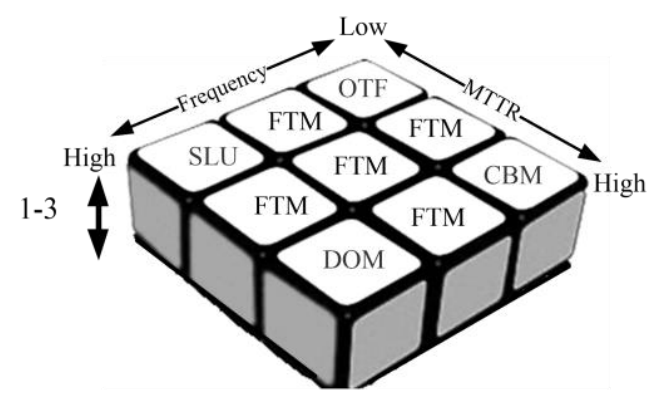

Figure 5. Proposed DMG, considering level one of failure detection rate 


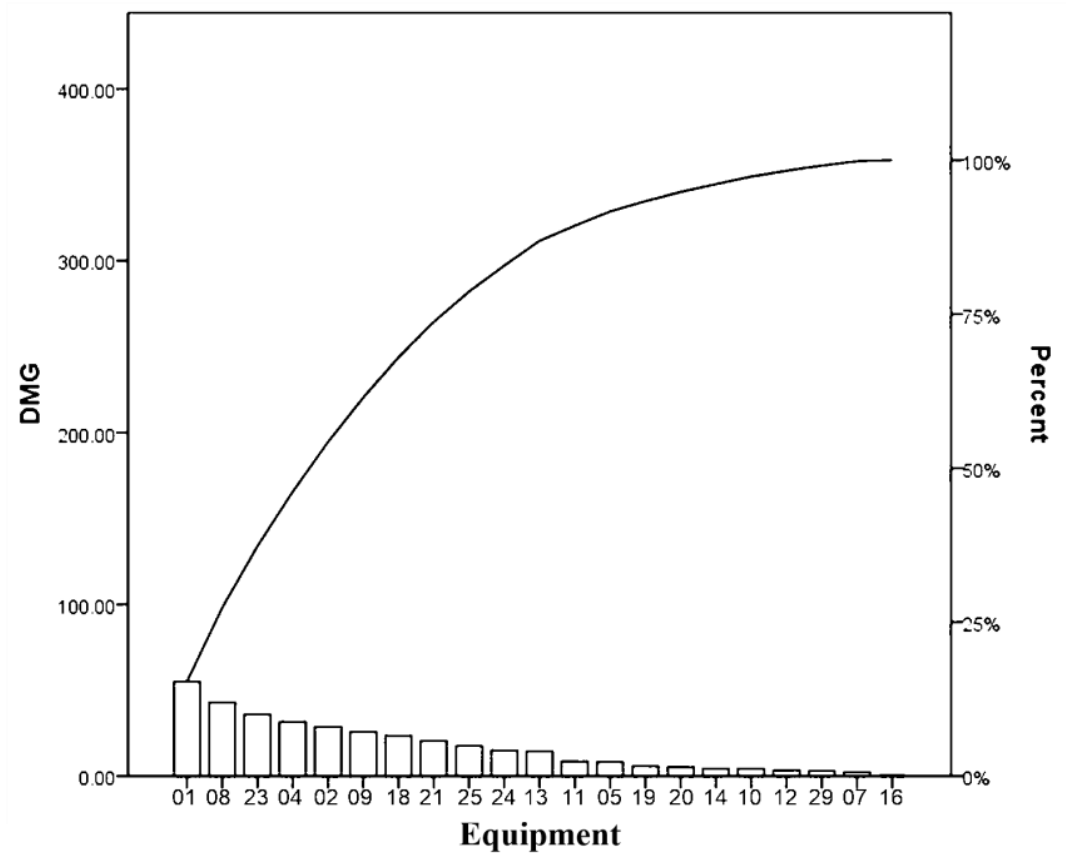

Figure 6. Pareto diagram for equipments based on DMG results

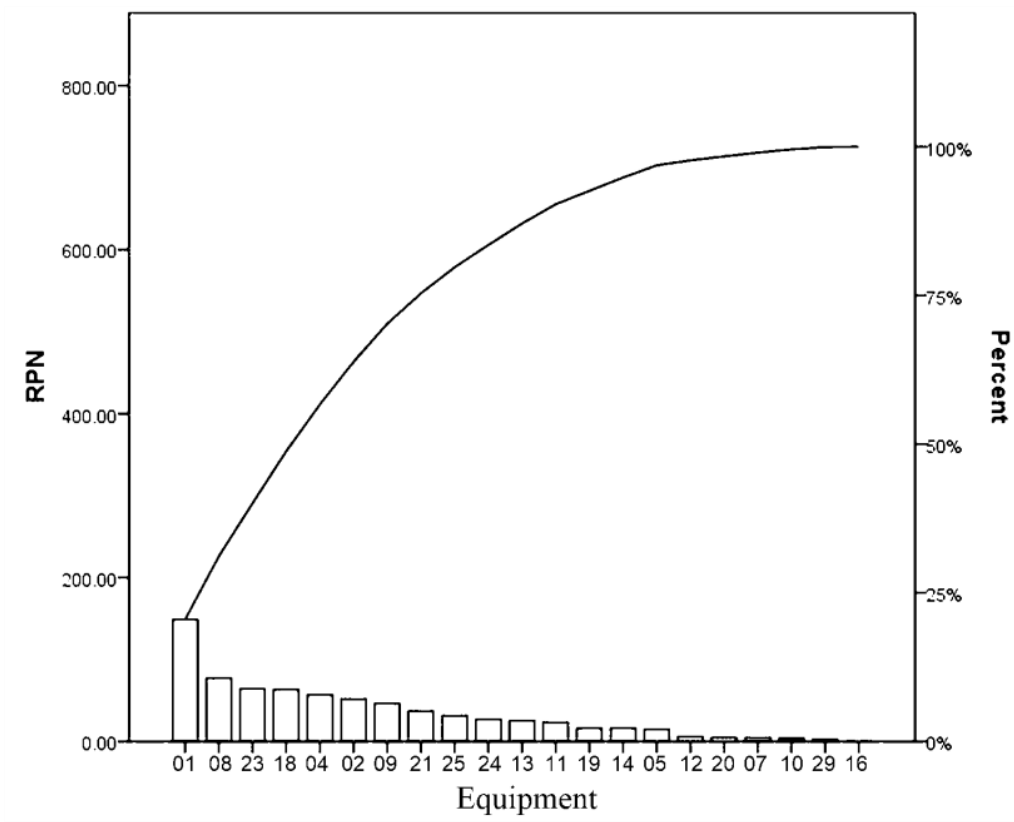

Figure 7. Pareto diagram for equipments based on RPN 


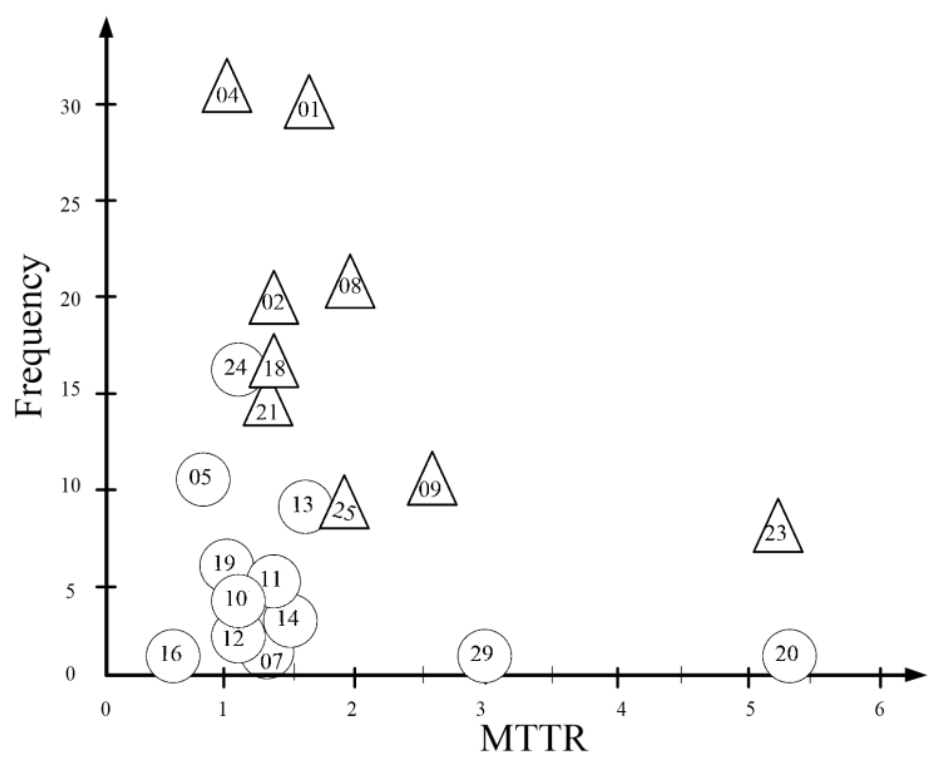

Figure 8. Condition of equipments based on Pareto principle considering DMG results

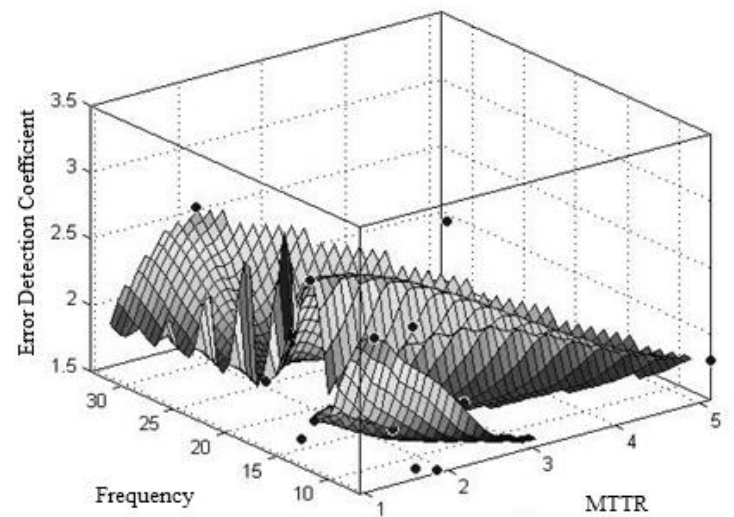

Figure 9. Equipments condition based on Pareto principle considering RPN results 
Table 1. CM techniques (Kelly, 2006)

\begin{tabular}{|c|c|c|c|}
\hline Type & Technique & On/off line & $\begin{array}{c}\text { Manual/ } \\
\text { automated }\end{array}$ \\
\hline \multirow{3}{*}{ Visual } & Human eye & On/off & Manual \\
\hline & Optical probes & Off & Manual \\
\hline & Closed circuit television (CCTV) & Off & Manual \\
\hline \multirow[t]{4}{*}{ Temperature } & Temperature crayons, paints and tapes & On & Manual \\
\hline & Thermometers ,thermocouples & On & Manual/automated \\
\hline & Infrared meter & On & Manual \\
\hline & Infrared camera & On & Manual \\
\hline \multirow[t]{3}{*}{ Lubricant } & Magnetic plugs and filters & On/off & Manual \\
\hline & Ferrography & N/A & Manual \\
\hline & Spectroscopy & N/A & Manual \\
\hline \multirow[t]{4}{*}{ Vibration } & Overall vibration level & On & Manual/automated \\
\hline & Frequency (spectrum) analysis & On & Manual/automated \\
\hline & $\begin{array}{l}\text { Shock-pulse monitoring (SPM), spike } \\
\text { energy and kurtosis }\end{array}$ & On & Manual/automated \\
\hline & Structural monitoring & Off & Manual \\
\hline \multirow[t]{6}{*}{ Crack } & Dye penetrant & On/Off & Manual \\
\hline & Magnetic flux & On/Off & Manual \\
\hline & Eddy current & On/Off & Manual \\
\hline & Ultrasonic & On/Off & Manual \\
\hline & Radiography & Off & - \\
\hline & Electrical resistance & On/Off & Manual \\
\hline \multirow[t]{4}{*}{ Corrosion } & Weight loss coupons & Off & Manual \\
\hline & Polarization resistance & On & - \\
\hline & Incremental bore holes & On & Manual \\
\hline & Electrical resistance & On & Manual/automated \\
\hline
\end{tabular}


Table 2. Determined levels for failure detection rate

\begin{tabular}{ll}
\hline Determined Levels & Descriptions \\
\hline $\begin{array}{l}\text { Level one } \\
\text { (interval one to three) }\end{array}$ & $\begin{array}{l}\text { The equipments located in this level have highly or definitely the chance } \\
\text { that existing controls recognize the failure reasons or modes. }\end{array}$ \\
Level two & The equipments located in this level on average have the chance that \\
(interval three to six) & $\begin{array}{l}\text { existing controls recognize the failure reasons or modes. } \\
\text { Level three }\end{array}$ \\
$\begin{array}{l}\text { The equipments located in this level have very low or unclear chance that } \\
\text { (interval six to nine) }\end{array}$ & existing controls recognize the failure reasons or modes. \\
\hline
\end{tabular}

Table 3. Adopting failure detection rate by $\mathrm{CM}$ techniques

\begin{tabular}{lll}
\hline Level & Failure Detection Rate & CM Technique \\
\hline 1 & Highest rate detection, & Polarization resistance \\
& interval 1 to 3 & Spectroscopy \\
& & Weight loss coupons \\
& Incremental bore holes \\
\hline 2 & Medium detection rate, & Optical probes \\
& interval 3 to 6 & Shock-pulse monitoring (SPM), spike energy and kurtosis \\
& & Infrared camera \\
& Magnetic flux \\
& Infrared meter \\
& Ultrasonic \\
& Structural monitoring \\
& Temperature crayons, paints and tapes \\
& Eddy current \\
& Magnetic plugs and filters \\
& Closed circuit television (CCTV) \\
& Frequency (spectrum) analysis \\
& Electrical resistance (corrosion) \\
& Ferrography (iron survey) \\
& Electrical resistance (gap survey) \\
& Human eye \\
& Dye penetrant (penetrate dye) \\
& Thermometers, thermocouples \\
& Overall vibration level \\
& Radiography \\
\hline &
\end{tabular}


Table 4. CM techniques related to the cells of level one of failure detection rate

\begin{tabular}{lll}
\hline Cell & Equipment code & Technique \\
\hline OTF $_{1,1,1}$ & 13 & Polarization resistance, \\
& 10 & Spectroscopy, polarization resistance, weight loss coupons \\
& 07 & Polarization resistance, weight loss coupons \\
& $11,16,12,19$, and 05 & Spectroscopy \\
\hline FTM $_{2,1,1}$ & 25 & Incremental bore holes \\
& 29 & Weight loss coupons \\
& 09 & Polarization resistance, weight loss coupons \\
\hline FTM $_{1,2,1}$ & 24 & Incremental bore holes \\
& 02 & Weight loss coupons \\
& 18 & Incremental bore holes, weight loss coupons \\
& 21 & Spectroscopy, weight loss coupons \\
\hline FTM $_{2,3,1}$ & 01 & Spectroscopy, weight loss coupons \\
\hline FTM $_{2,2,1}$ & 08 & Incremental bore holes \\
\hline $\mathrm{CBM}_{3,1,1}$ & 20 & Incremental bore holes, weight loss coupons \\
\hline SLU $_{1,3,1}$ & 04 & Spectroscopy, weight loss coupons \\
\hline & & Incremental bore holes, weight loss coupons \\
\hline
\end{tabular}

Table 5. Calculation of RPN for each equipment

\begin{tabular}{|c|c|c|c|c|c|}
\hline Equipment name and code & MTTR & Frequency & $\begin{array}{l}\text { Detection } \\
\text { rate }\end{array}$ & RPN & DMG \\
\hline 18 Primary Cooling & 1.47 & 16 & 2.7 & 63.50 & 23.52 \\
\hline 21 Mould Level Control (MLC) & 1.47 & 14 & 1.8 & 37.04 & 20.58 \\
\hline 23 Resonance Mould & 5.14 & 7 & 1.8 & 64.72 & 35.95 \\
\hline 08 Segment 1 to 5 & 1.95 & 22 & 1.8 & 77.22 & 42.90 \\
\hline 09 Straightener and Withdrawal & 2.58 & 10 & 1.8 & 46.44 & 25.80 \\
\hline 13 Cutting Machine & 1.60 & 9 & 1.8 & 25.92 & 14.40 \\
\hline 01 Continuous Casting Machine & 1.84 & 30 & 2.7 & 149.04 & 55.20 \\
\hline 14 Roller Table Pusher & 1.50 & 3 & 3.6 & 16.20 & 4.50 \\
\hline 05 Tundish Preheating Station & 0.75 & 11 & 1.8 & 14.85 & 8.25 \\
\hline 11 Dumy Bar Car & 1.46 & 6 & 2.7 & 23.65 & 8.76 \\
\hline 02 Ladle Turret & 1.44 & 20 & 1.8 & 51.84 & 28.80 \\
\hline 07 Oscillator & 1.26 & 2 & 1.8 & 4.54 & 2.52 \\
\hline 04 Tundish Car & 0.96 & 33 & 1.8 & 57.03 & 31.68 \\
\hline 10 Dumy Bar Ramp & 1.11 & 4 & 0.9 & 3.99 & 4.44 \\
\hline 16 Slab Pusher & 0.65 & 1 & 0.9 & 0.59 & 0.65 \\
\hline 19 Secondary Cooling & 1.00 & 6 & 2.7 & 16.20 & 6.00 \\
\hline 12 Exhauster & 1.14 & 3 & 1.8 & 6.16 & 3.42 \\
\hline 20 Cooling Tower & 5.35 & 1 & 0.9 & 4.82 & 5.35 \\
\hline 24 Segment 6 to 11 & 1.16 & 13 & 1.8 & 27.15 & 15.08 \\
\hline 25 Soft Water & 1.96 & 9 & 1.8 & 31.75 & 17.64 \\
\hline 29 Secondary Water Tank & 3.00 & 1 & 0.9 & 2.70 & 3.00 \\
\hline
\end{tabular}


Table 6. Comparing the ranking of equipment based on the results of 2D-DMG and 3DDMG (RPN based)

\begin{tabular}{cc}
\hline 2D-DMG & 3D-DMG (RPN based) \\
\hline 1 & 1 \\
8 & 8 \\
23 & 23 \\
4 & 18 \\
2 & 4 \\
9 & 2 \\
18 & 9 \\
21 & 21 \\
25 & 25 \\
24 & 24 \\
13 & 13 \\
11 & 11 \\
5 & 19 \\
19 & 14 \\
20 & 5 \\
14 & 12 \\
10 & 20 \\
12 & 7 \\
29 & 10 \\
7 & 29 \\
16 & 16 \\
\hline
\end{tabular}

Table 7. CM techniques and tools used for each equipment in MSC

\begin{tabular}{|c|c|c|c|c|c|}
\hline & Equipment code and name & $\begin{array}{l}\text { Vibration } \\
\text { Analysis }\end{array}$ & Thermography & $\begin{array}{l}\text { Inspection } \\
\text { Standard }\end{array}$ & $\begin{array}{l}\text { Service } \\
\text { Standard } \\
\text { (routin) }\end{array}$ \\
\hline$\overline{18}$ & Primary Cooling & & & $\checkmark$ & $\checkmark$ \\
\hline 21 & Mould Level Control (MLC) & & $\checkmark$ & $\checkmark$ & $\checkmark$ \\
\hline 23 & Resonance Mould & $\checkmark$ & $\checkmark$ & $\checkmark$ & $\checkmark$ \\
\hline 08 & Segment 1 to 5 & $\checkmark$ & $\checkmark$ & $\checkmark$ & $\checkmark$ \\
\hline 09 & Straightener and Withdrawal & $\checkmark$ & $\checkmark$ & $\checkmark$ & $\checkmark$ \\
\hline 13 & Cutting Machine & & & $\checkmark$ & $\checkmark$ \\
\hline 01 & Continuous Casting Machine & & & $\checkmark$ & $\checkmark$ \\
\hline 14 & Roller Table Pusher & & $\checkmark$ & $\checkmark$ & $\checkmark$ \\
\hline 05 & Tundish Preheating Station & & & $\checkmark$ & $\checkmark$ \\
\hline 11 & Dumy Bar Car & & & $\checkmark$ & $\checkmark$ \\
\hline 02 & Ladle Turret & & $\checkmark$ & $\checkmark$ & $\checkmark$ \\
\hline 07 & Oscillator & & $\checkmark$ & $\checkmark$ & $\checkmark$ \\
\hline 04 & Tundish Car & & $\checkmark$ & $\checkmark$ & $\checkmark$ \\
\hline 10 & Dumy Bar Ramp & & & $\checkmark$ & $\checkmark$ \\
\hline 16 & Slab Pusher & & & $\checkmark$ & $\checkmark$ \\
\hline 19 & Secondary Cooling & & & $\checkmark$ & $\checkmark$ \\
\hline 12 & Exhauster & $\checkmark$ & & $\checkmark$ & $\checkmark$ \\
\hline 20 & Cooling Tower & $\checkmark$ & & $\checkmark$ & $\checkmark$ \\
\hline 24 & Segment 6 to 11 & $\checkmark$ & $\checkmark$ & $\checkmark$ & $\checkmark$ \\
\hline 25 & Soft Water & & & $\checkmark$ & $\checkmark$ \\
\hline 29 & Secondary Water Tank & & & $\checkmark$ & $\checkmark$ \\
\hline
\end{tabular}

